\title{
Transcription of genes near the SspE locus of the Bacillus subtilis genome
}

\author{
Hiroki Yamamoto, Masao Mori and Junichi Sekiguchi \\ Author for correspondence: Junichi Sekiguchi. Tel: +81268215344 . Fax: +81268215331. \\ e-mail: jsekigu(ä) giptc.shinshu-u.ac.jp
}

Department of Applied Biology, Faculty of Textile Science and Technology, Shinshu University, 3-15-1 Tokida, Ueda-shi, Nagano 386-8567, Japan

\begin{abstract}
The yfhP, yfhQ (mutY homologue), yfhS and yfhR (oxidoreductase homologue) genes, which are located upstream of the SspE locus, have been identified in the Bacillus subtilis genome. Transcriptional analysis showed that yfhP, yfhQ and $y$ fhR are transcribed during the exponential growth phase, and sspE is monocistronically transcribed in the late sporulation phase and co-transcribed with yfhQ and/or yfhR during exponential growth. However, SspE was not translated during this period. Northern blot and primer extension analyses indicated that $y$ fhS is transcribed by $E \sigma^{E}$ during sporulation. No significant difference between wild-type and yfhS mutant strains was found in the rate of sporulation or germination, the heat tolerance of spores or the transcription of the sspE locus during sporulation. The transcription of the $y f h P$ and yfhQ-yfhR-sspE loci increased 2.5- and 5.3-fold in a yfhP-deficient strain compared to the wild-type strain at $t_{-2}$ ( $2 \mathrm{~h}$ before initiation of sporulation). In addition, transcription corresponding to the $y f h R-s s p E$ loci increased more than twofold with maximum values observed at $t_{-1.5}$. These results suggest that YfhP may act as a negative regulator for the transcription of yfhQ, yfhR, sspE and yfhP.
\end{abstract}

Keywords: genome analysis, sspE region, MutY homologue, oxidoreductase homologue, transcriptional regulation

\section{INTRODUCTION}

Analysis of the Bacillus subtilis genome sequence has revealed ORFs $y f h P, y f h Q$ and $y f h R$ upstream of the $s s p E$ locus (Kunst et al., 1997). sspE encodes a small acid-soluble spore protein and is monocistronically transcribed by $E \sigma^{\mathrm{G}}$ at stage III of sporulation (Hackett \& Setlow, 1987; Fajardo-Cavazos et al., 1991). yfhQ probably encodes a $B$. subtilis $m u t Y$ counterpart since it has high similarity to the $\mathrm{A} / \mathrm{G}$-specific adenine glycosylase of Escherichia coli (38.0\% identity over 271 residues) (Michaels et al., 1990). YfhP appears to be a $37 \cdot 1 \mathrm{kDa}$ basic membrane-anchored protein without any significant similarity to known proteins.

A small ORF, designated $y f h S$, which was not referred to by Yamamoto et al. (1996), encodes a protein of 74 aa with a molecular mass of $8797 \mathrm{Da}$. We report here data on the transcriptional analysis of $y f h P, y f h Q, y f h S$ and $y f h R$, and regulation of transcription of the $y f h P$ and $y f h Q-y f h R-s s p E$ operons by $y f h P$ during exponential growth.

\section{METHODS}

Bacterial strains, plasmids and culture conditions. The bacterial strains and plasmids used in this study are listed in Table 1. Bacteria were cultured in $\mathrm{LB}$ medium $\left(\mathrm{g} \mathrm{l}^{-1}\right.$ : yeast extract, $5 ;$ tryptone, $10 ; \mathrm{NaCl}, 5 ; \mathrm{pH} 7 \cdot 2)$ at $37^{\circ} \mathrm{C}$. Ampicillin or erythromycin was added to a final concentration of 50 or $0 \cdot 3 \mu \mathrm{g} \mathrm{m})^{-1}$, respectively. Schaeffer medium (Schaeffer et al., 1965) was used for B. subtilis sporulation.

Plasmid construction. Derivatives of pMUTIN1 (Vagner et al., 1998) and pGEM3zf $(+)$ (Promega) were used to construct mutants of $B$. subtilis and to prepare gene-specific RNA probes, respectively. Plasmids $\mathrm{pMYFHQ}$, pMYFHS and pMSSPE were constructed by cloning Hindlll-Bam HI fragments of PCR products amplified with primers HYFHQ and BYFHQ, hSHF and hSBR, and HSSPE and BSSPE into vector pMUTIN1, respectively (Table 2 and Fig. 1). These HindIIIBam HI-digested PCR fragments were also cloned into pGEM3zf $(+)$ to generate plasmids pGYFHQ, pGYFHS and pGSSPE, respectively. To clone the internal region of $y f h R$, the $2.4 \mathrm{~kb}$ fragment amplified with primers HYFHQ and BSSPE was digested with HindIII and $B g l I I$ and the resultant 445 bp HindIII-BglII fragment was ligated into the HindIII/ Bam $\mathrm{HI}$ sites of pMUTIN1 and pGEM $3 \mathrm{zf}(+)$ to generate 
Table 1. Bacterial strains and plasmids used in this study

\begin{tabular}{|c|c|c|}
\hline $\begin{array}{l}\text { Strain or } \\
\text { plasmid }\end{array}$ & Relevant genotype & $\begin{array}{l}\text { Source or } \\
\text { reference }\end{array}$ \\
\hline \multicolumn{3}{|l|}{ Bacillus subtilis } \\
\hline 168 & $\operatorname{trp}) \mathrm{C} 2$ & D. Ehrlich \\
\hline YFHPd & $\operatorname{trp} C 2 y f h P:: \mathrm{pMYFHP}$ & This study \\
\hline YFHQd & $\operatorname{trp} \mathrm{C} 2$ yfhQ::pMYFHQ & This study \\
\hline YFHSd & $\operatorname{trp} \mathrm{C} 2$ yfhS : :pMYFHS & This study \\
\hline YFHRd & $\operatorname{trp} C 2$ yfhR::pMYFHR & This study \\
\hline SSPE.d & $\operatorname{trp}(2$ sspE::pMSSPE & This study \\
\hline SELZ & $\operatorname{trp} C 2 \operatorname{ssp} E:: \mathrm{pMSELZ}$ & This study \\
\hline$A M L Z$ & $\operatorname{trp}(2$ amyE::(cat lac $Z)$ & This study \\
\hline AMP2 2 & $\begin{array}{l}\operatorname{trp}\left(: 2 \text { amyE: : (cat } \mathrm{P}_{y f h Q}\right. \\
y f b Q-l a c Z)\end{array}$ & This study \\
\hline AMP 345 & $\begin{array}{l}\operatorname{trp} C 2 \text { amyE: : (cat } \mathrm{P}_{y f h R} \\
y f h R-l a c Z)\end{array}$ & This study \\
\hline IS38 & $\operatorname{trp} C 2$ spollIC 94 & BGSC \\
\hline IS60) & leuA8 tal-1 spollG41 & BGSC \\
\hline spoliIG $\Delta 1$ & $\operatorname{trp} C 2$ spolllG $\mathrm{s} \Delta 1$ & P. Setlow \\
\hline 497.1 & $\operatorname{trpC} 2$ spollID 83 & Kunkel et al. (1988) \\
\hline HSIIID & $\begin{array}{l}\operatorname{trp}(2 \text { spoIIID } 83 \\
y f h S:: \text { pMYFHS }\end{array}$ & YFHSd $\rightarrow 497.1 \dagger$ \\
\hline \multicolumn{3}{|l|}{ Escherichia coli } \\
\hline JM 109 & 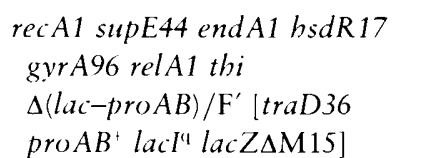 & Takara Shuzo \\
\hline $\mathrm{C} 600$ & $\begin{array}{l}\text { supE44 hsdR thi-1 thr-1 leuB6 } \\
\text { lacY1 tonA21 }\end{array}$ & Laboratory stock \\
\hline \multicolumn{3}{|l|}{ Plasmid } \\
\hline pMUTINI & erm bla lacZ lacl Pspac & Vagner et al. (1998) \\
\hline pGEM $3 z \mathrm{f}(+)$ & bla lacZ & Promega \\
\hline PMYFHP & pMUTIN1:: $\Delta y f h P$ & This study \\
\hline pMYFHQ & pMUTIN $1:: \Delta y f h Q$ & This study \\
\hline pMYFHS & pMUTIN $1:: \Delta y f h S$ & This study \\
\hline PMYFHR & pMUTIN $1:: \Delta y f h R$ & This study \\
\hline pMSSPE & pMUTIN1:: $\Delta s s p E$ & This study \\
\hline pMSELZ & $\begin{array}{l}\text { pMUTIN1::sspE-lacZ } \\
\text { translational fusion }\end{array}$ & This study \\
\hline pGY'FHP & pGEM3zf $(+):: \Delta y f h P$ & This study \\
\hline pGYFHQ & pGEM3zf $(+):: \Delta y f h Q$ & This study \\
\hline pGYFHS & pGEM3zf $(+):: \Delta y f h S$ & This study \\
\hline pCiYFHR & pGEM $3 z f(+):: \Delta y f h R$ & This study \\
\hline pGSSPE & pGEM $3 z f(+):: \Delta s s p E$ & This study \\
\hline pDH88 & bla cat lacl Pspac & Henner $(1990)$ \\
\hline pDHAF & $\begin{array}{l}\text { bla cat lacl Pspac } \triangle a m y E \text { (front } \\
\text { region) }\end{array}$ & This study \\
\hline pDHAFB & bla amyE:: (cat lacI Pspac) & This study \\
\hline pDHAFBLZ & bla amyE: (cat lac $Z)$ & This study \\
\hline pDHLZP2 & $\begin{array}{l}\text { bla amyE: }\left(\text { cat } \mathrm{P}_{y f h Q}\right. \\
\text { yfhQ-lacZ) }\end{array}$ & This study \\
\hline pDHLZP345 & $\begin{array}{l}\text { bla amyE: : (cat } \mathrm{P}_{y f h R} \\
\text { yfhR-lacZ) }\end{array}$ & This study \\
\hline
\end{tabular}

*BGSC, Bacillus Genetic Stock Center, Ohio State University, USA ; D. Ehrlich, INRA, Jouy-en-Josas, France; P. Setlow, Health Center, Farmington, CT, USA.

†B. subtilis 497.1 was transformed by YFHSd DNA. 
Table 2. Primers used in this study

\begin{tabular}{|c|c|c|}
\hline Primer & Sequence $\left(5^{\prime} \rightarrow 3^{\prime}\right)$ or source & $\begin{array}{c}\text { Restriction } \\
\text { enzyme }\end{array}$ \\
\hline HYFHQ & GCCGAAGCTTAGACATACAGCAATTTCGC & HindlII \\
\hline BYFHQ & GCGCGGATCCAACAATGCCGCCGTATTC & Bam HI \\
\hline hSHF & GCCGAAGCTTATGAGCGAATTGAACATGG & HindIII \\
\hline hSBR & GCGGGATCCTCAATTTCTTGCGTTAATTCC & Bam HI \\
\hline HSSPE & GCCGA AGCTTGCTAACTCAAATAACTTCAGC & HindIII \\
\hline BSSPE & CGCGGATCCCTGTCTTACCTGCTGTGC & $\mathrm{Bam} \mathrm{HI}$ \\
\hline BYFHP & GCGCGGATCCTACCAAATCGCGATAGCTG & Bam HI \\
\hline HFLZsE & CGGCAAGCTTGAAGATCTGCTTGAGGATG & HindIII \\
\hline SRLZsE & GCGCGTCGACCATTGTTATCACCTCCAC & SalI \\
\hline AFSma-1F & TCCCCCGGGTGATTTGTATTCACTCTGCC & SmaI \\
\hline$A B \times A-3 R$ & GCTCTAGACGTCTTTTGCGTTGGTTGTATCC & AatII \\
\hline ABEco- $2 \mathrm{~F}$ & CCGG $\boldsymbol{A} \boldsymbol{A} T \boldsymbol{T} \boldsymbol{C A A A T G C A G G T T C A T C C T C T G ~}$ & EcoRI \\
\hline P2MUTY-1E & GCGCG $\boldsymbol{A} \boldsymbol{A} \boldsymbol{T} T C A A A G A C A T G C A G A A C G A C$ & EcoRI \\
\hline P2MUTY-2S & GCCGCCCGGGTTTGTCTTCAAGTACGTTC & SmaI \\
\hline P345HR-1E & GCGCGAATTCCCGAATCTTGAAAC & EcoRI \\
\hline P345HR-2S & GCCGCCCGGGTGCTTCCTGTTACGAGTG & SmaI \\
\hline$-21 \mathrm{M} 13$ & Universal primer (Takara) & \\
\hline M13RV & Universal primer (Takara) & \\
\hline yfhP-ex1 & GATCATAACAGCGTGAGC & \\
\hline yfhQ-ex1 & CTCTCGTTCAAACCATGAG & \\
\hline yfhR-ex1 & CGTGCATAGTTAATGACG & \\
\hline yfhR-ex2 & GTTATGTATGTCGGACGTG & \\
\hline yfhR-ex3 & TCTCTTACGATTAAGAATGG & \\
\hline yfhS-ex1 & GTTCACTGTTCTTCCAATC & \\
\hline
\end{tabular}

"Additional sequences which do not correspond to the sequences near the $s s p E$ locus are italicized. Restriction sites for the enzymes listed in the third column are shown in bold.

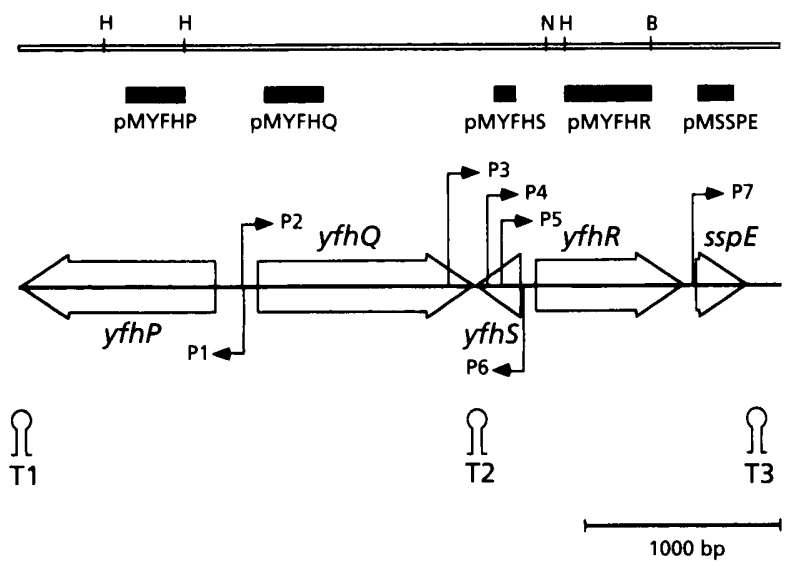

Fig. 1. Physical map and gene organization of the $y f h P$, yfhQ, $y$ fhS, $y f h R$ and sspE loci. yfhS is a gene newly identified in this study. The five deduced ORFs and their transcriptional and translational directions are indicated by arrows and arrowheads, respectively. Plasmids used as specific probes for Northern analysis are shown above the map and the thick bars indicate the regions cloned into the parent plasmid, pMUTIN1. The deduced $\rho$-independent terminators are denoted as follows: $\mathrm{T} 1, \Delta G=-18.4 \mathrm{kcal} \mathrm{mol}^{-1} ; \mathrm{T} 2, \Delta G=-22.7 \mathrm{kcal} \mathrm{mol}^{-1}$; T3, $\Delta G=-32.8 \mathrm{kcal} \mathrm{mol}^{-1}$. The hooked arrows indicate the transcriptional start points and directions, as shown in Fig. 4. $\mathrm{H}$, $\mathrm{N}$ and $\mathrm{B}$ denote HindIII, Notl and Bg/II sites, respectively. plasmids pMYFHR (Fig. 1) and pGYFHR, respectively. To clone the internal region of $y f h P$, the $1.0 \mathrm{~kb}$ fragment amplified with primers BYFHP and BYFHQ was digested with HindIII and $B a m \mathrm{HI}$ and the resultant 300 bp HindIII-BamHI fragment was ligated into the HindIII/Bam HI sites of pMUTIN1 and pGEM3zf $(+)$ to generate plasmids pMYFHP (Fig. 1) and pGYFHP, respectively. For construction of the sspE-lacZ translational fusion strain, a 229 bp PCR product with primers HFLZsE and SRLZsE was digested with HindIII and SalI. The resulting fragment was cloned into the HindIII/Sall sites of pMUTIN1 in-frame with the lacZ coding region to obtain pMSELZ.

Northern blot analysis. A culture suspension was centrifuged at various time points during growth. Each pellet $\left(\mathrm{OD}_{600}=\right.$ 20) was washed in $1 \mathrm{ml}$ chilled killing buffer (Volker et al., 1994). After centrifugation, the pellet was resuspended in $1 \mathrm{ml}$ SET buffer (Kuroda \& Sekiguchi, 1993) containing $6 \mathrm{mg}$ lysozyme. The suspension was kept on ice for $15 \mathrm{~min}$ and then centrifuged for $1 \mathrm{~min}$ in a microcentrifuge. The pellet was used for RNA preparation with ISOGEN (Nippon Gene) according to the manufacturer's instructions. Northern blot analysis of RNAs fractionated by electrophoresis in agarose/ formaldehyde gels was performed as described by Sambrook et al. (1989). Probe labelling was performed with a DIG RNA Labelling Kit (Boehringer Mannheim) according to the manufacturer's instructions with some minor modifications. Briefly, the internal regions cloned into pGEM3zf $(+)$ derivatives corresponding to individual genes were amplified by PCR with 
primers $-21 \mathrm{M} 13$ and M13RV. The amplified fragments were digested with Hindlll and used as templates for in vitro run-off transcription with T7 RNA polymerase. Hybridization signals were quantified using NIH lmage 1.55 software.

Primer extension analysis. Primer extension analysis was performed as described previously (Kuroda \& Sekiguchi, 1993) with end-labelled primers yfhP-exl, yfhQ-ex1, yfhRex $1, y$ fhR-ex2, yfhR-ex3 and ythS-ex1 (Table 2). The reaction products were quantified using a PhosphorImager system and ImageQuant software (Molecular Dynamics).

Construction and phenotypic characterization of yfhP, yfhQ. yfhS, yfhR and sspE mutants, and a sspE-lacZ translational fusion strain. Conventional transformation of $B$. subtilis was performed by the procedure of Anagnostopoulos \& Spizizen (1961). Strains YFHPd, YFHQd, YFHSd, YFHRd, SSPEd and SELZ were constructed by integration of pMYFHP, pMYFHQ, pMYFHS, pMYFHR, pMSSPE and pMSELZ, respectively. Correct integration was confirmed by Southern hybridization. The morphology, growth rate, sporulation frequency and germination of mutants were tested.

Construction of transcriptional fusion strains between putative promoters and lac $Z$ at the amyE locus. To obtain transcriptional fusion strains between putative promoters upstream of $y f h Q$ and $y f h R$, and the lac $Z$ gene, plasmid pDHAFBLZ was constructed. An amyE front region was amplified with primers AFSma-1F and ABXA-3R and the amplified fragment $(2.05 \mathrm{~kb})$ was digested with ClaI and SmaI. A $0.7 \mathrm{~kb}$ fragment was filled in with Klenow fragment and inserted into the Bst 11071 and Tth111I sites of pDH88 to obtain $\mathrm{pDHAF}$. To generate $\mathrm{pDHAFB}$, an amyE back region was amplified with primers $A B E c 0-2 F$ and $A B X A-3 R$ and the amplified fragment $(0.63 \mathrm{~kb})$ was digested with Aatll and EcoRI. The resulting fragment was ligated with AatII/EcoRIdigested pDHAF. Finally, to obtain pDHAFBLZ, a $3.26 \mathrm{~kb}$ EcoRI-Dral fragment (containing lac Z) from pMUTIN1 was inserted into the EcoRI and EcoRV sites of pDHAFB. A $0.56 \mathrm{~kb}$ fragment containing the $\mathrm{P} 2$ promoter region was amplified with primers P2MUTY-1E and P2MUTY-2S and ligated into the EcoRI and SmaI sites of pDHAFBLZ to obtain pDHLZP2. A $0.65 \mathrm{~kb}$ fragment containing P3, P4 and P5 promoter regions was amplified with primers $\mathrm{P} 345 \mathrm{HR}-1 \mathrm{E}$ and P345HR-2S. The amplified fragment was cloned into pDHABLZ to construct pDHLZP345 as described above. pDHLZP2, pDHLZP345 and pDHAFBLZ were linearized with $S c a l$ and used for transformation of strain 168 , resulting in strains AMP2, AMP345 and AMLZ, respectively. Correct integration of the plasmids into the strains was confirmed by examining halo formation on starch plates and long-range PCR.

$\boldsymbol{\beta}$-Galactosidase assay. Cells were pre-cultured on Schaeffer agar plates without antibiotics at $30^{\circ} \mathrm{C}$ for $10 \mathrm{~h}$. Cells were then inoculated into $100 \mathrm{ml}$ fresh Schaeffer medium at a density of $\mathrm{OD}_{600}=0.01$ and grown at $37^{\circ} \mathrm{C}$. The $\beta$-galactosidase assay was carried out as described by Shimotsu \& Henner (1986). One unit of $\beta$-galactosidase activity was defined as the amount of enzyme necessary to release 1 nmol 2nitrophenol from ONPG in $1 \mathrm{~min}$.

\section{RESULTS AND DISCUSSION}

\section{Northern blot analysis and primer extension analysis}

Figs 2-4 show the results of Northern hybridization and primer extension analysis of transcripts. The interpret- ation of these results is summarized in Table 3 . The $s s p E$-specific probe was hybridized with a $0.3 \mathrm{~kb}$ transcript at $2.5\left(t_{2 \cdot 5}\right)$ and $5 \mathrm{~h}\left(t_{5}\right)$ after initiation of sporulation (Fig. 2e). This signal corresponds to a transcript which starts from the $\mathrm{E} \sigma^{(i}$-driven promoter described by Hackett \& Setlow (1987) and FajardoCavazos et al. (1991). A weak signal corresponding to $1.8 \mathrm{~kb}$ was also detected (Fig. 2e). This signal does not correspond to an area covered by both $y f h R$ and sspE, since the $y f h R$-specific probe did not hybridize with it (Fig. 2c). Therefore, it may have resulted from a readthrough transcript downstream of the $\mathrm{T} 3$ terminator (Fig. 1). On the other hand, three transcripts estimated to be $1.3 \mathrm{~kb}(y f h R-s s p E), 1.5 \mathrm{~kb}(y f h R-s s p E)$ and $2.6 \mathrm{~kb}$ $(y f h Q-y f h R-s s p E)$ were detected during the exponential growth phase (Fig. 2c, e). $y f h Q$ was transcribed as a $2.6 \mathrm{~kb}$ mRNA and a $1.2 \mathrm{~kb}$ monocistronic mRNA in the same period (Fig. 2b). Moreover, $y f h P$ was monocistronically transcribed during the exponential growth phase (Fig. 2a). As shown in Fig. 2(d), the $y f h S$-specific probe hybridized with a $0.3 \mathrm{~kb}$ transcript at $t_{2 \cdot 5}$ and $t_{5}$. This suggests that $y f h S$ is a functional ORF monocistronically transcribed during sporulation.

To determine the start points of transcripts starting between $y f h Q$ and $y f h R$, primer extension was performed with oligonucleotides yfhR-ex1, yfhR-ex2 and yfhR-ex3. The results indicated that P4 (Fig. 3d) and P5 (Fig. 3e) are located in the region between the putative $\mathrm{T} 2$ terminator and $y f h R$ (Fig. $4 \mathrm{~b}$ ), whereas P3 (Fig. 3c) is located in an upstream region encoding the $C$ terminus of Y fhQ (Fig. 4b). As revealed by Northern blotting with the $y f h Q$-specific probe (Fig. $2 \mathrm{~b}$ ), the putative T2 terminator seems to be partially read through. The -35 and -10 regions found upstream of P3 and P5 show similarity to the $\sigma^{\mathrm{A}}$ consensus (Table 3 and Fig. 4b). This suggests that $\mathrm{P} 3$ and $\mathrm{P} 5$ are recognized by $\mathrm{E} \sigma^{\mathrm{A}}$. On the other hand, the promoter region of $\mathrm{P} 4$ does not correspond to the consensus sequence of any known $\sigma$ factors, including $\sigma^{\mathrm{A}}$ (Fig. $4 \mathrm{~b}$ ). Moreover, the transcript derived from $\mathrm{P} 4$ was very weak and we did not observe a corresponding signal on Northern blot analysis (Fig. 2c, e). However, a signal was observed by primer extension analysis with both yfhR-ex1 (data not shown) and yfhR-ex2 (Fig. 3d). We also tried to determine the $5^{\prime}$ ends of transcripts corresponding to $y f h Q$ or $y f h P$. A primer extension signal (P2) was obtained with primer yfhQ-ex1 and RNA from wild-type cells at $t_{-2}$ (Fig. $3 \mathrm{~b}$ ). Assuming that mRNAs which start from $\mathrm{P} 2$ end at the T2 and T3 terminators, the lengths of these transcripts would be 1.17 and $2.63 \mathrm{~kb}$, respectively. These data are consistent with the results of Northern blot analysis (Fig. 2b). In the case of $y f h P$, a primer extension signal (P1) was obtained with primer yfhP-ex1 and RNA from the cells at $t_{-2}$ (Fig. 3a). The $1.1 \mathrm{~kb}$ signal in Fig. 2(a) seems to correspond in size to mRNA which starts from P1 and stops at T1. The -35 (TTTTCT) and -10 (TAACAT) regions spaced $16 \mathrm{bp}$ apart were found upstream of $\mathrm{P} 2$, and the -35 (TTTTCT) and -10 (TACACT) regions spaced $18 \mathrm{bp}$ apart found upstream of P1 do not seem to correspond to the $\sigma^{\mathrm{A}}$ consensus 
Table 3. Various transcripts detected in the $y f h P Q R S$ and sspE loci

\begin{tabular}{|c|c|c|c|c|c|c|c|}
\hline $\begin{array}{l}\text { Start } \\
\text { point }\end{array}$ & $\begin{array}{c}\text { Size on } \\
\text { Northern blot } \\
(\mathbf{k b})^{*}\end{array}$ & $\begin{array}{c}\text { Corresponding } \\
\text { locus }\end{array}$ & $\begin{array}{c}\text { Expression } \\
\text { period }\end{array}$ & -35 region & Space & -10 region & $\begin{array}{l}\text { Sigma } \\
\text { factor }\end{array}$ \\
\hline P1 & $1 \cdot 1$ & $y f h P$ & Vegetative & TTTTCT & 16 & TACACT & $?$ \\
\hline \multirow[t]{2}{*}{$\mathrm{P} 2$} & $2 \cdot 6$ & $y f h Q-y f h R-s s p E$ & Vegetative & TTTTCT & 18 & TAACAT & $?$ \\
\hline & $1 \cdot 2$ & $y f h Q$ & Vegetative & - & - & - & \\
\hline P3 & $1 \cdot 5$ & $y f h R-s s p E$ & Vegetative & TGGAAT & 17 & TAAAGT & A \\
\hline P4 & ND & $y f h R-s s p E$ & Vegetative & - & - & - & $?$ \\
\hline P5 & $1 \cdot 3$ & $y f h R-s s p E$ & Vegetative & TTGGCC & 18 & CATAAT & A \\
\hline P6 & $0 \cdot 3$ & $y f h S$ & Sporulation & GCGTATA & 15 & CAAACAAT & $\mathrm{E}$ \\
\hline $\mathrm{P} 7 \dagger$ & $0 \cdot 3$ & $\operatorname{ssp} E$ & Sporulation & GAATA & 18 & CATTCTA & G \\
\hline
\end{tabular}

* ND, Not determined.

†The P7-initiated transcript was previously reported by Fajardo-Cavazos et al. (1991).

(a)

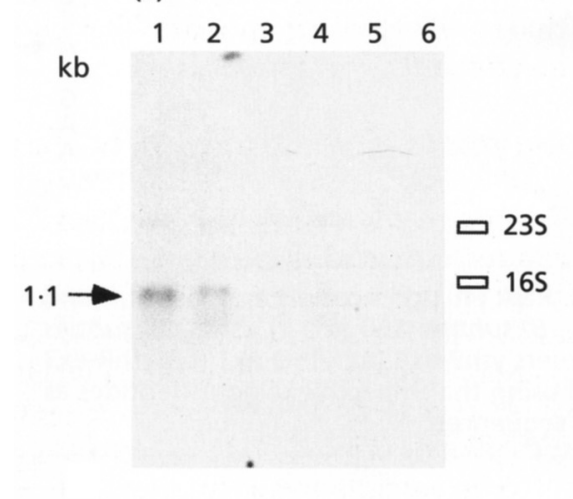

(d)

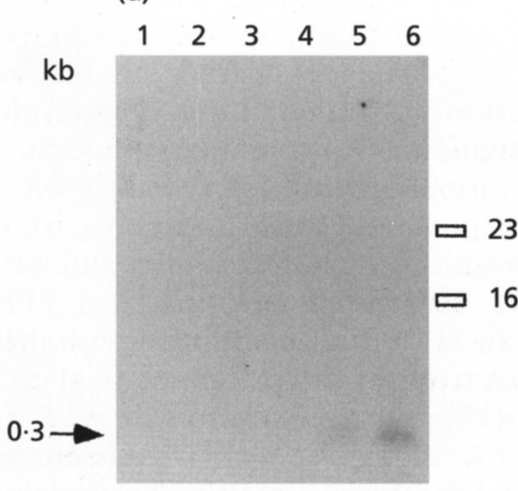

(b)

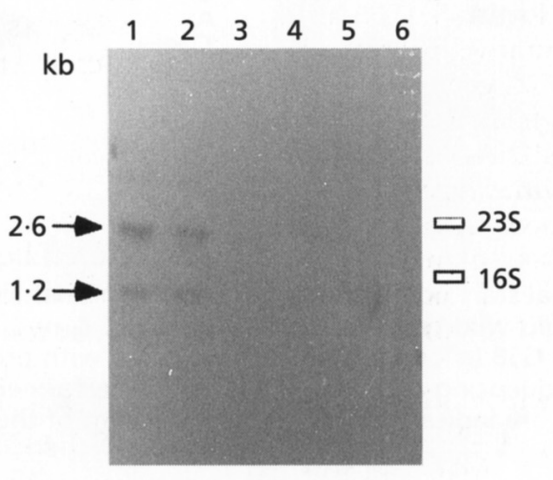

(e)

$\begin{array}{llllll}1 & 2 & 3 & 4 & 5 & 6\end{array}$

$\mathrm{kb}$

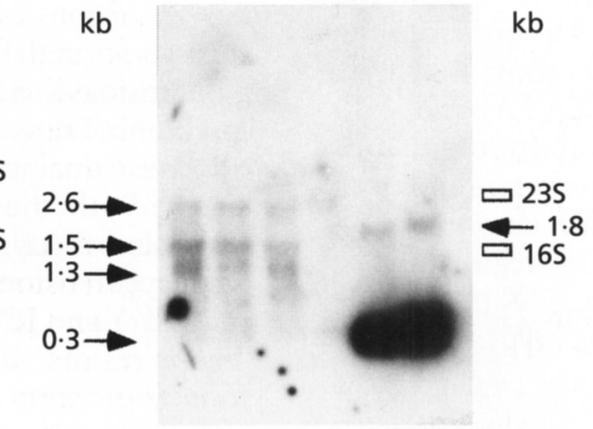

Fig. 2. Northern blot analysis with yfhP- (a), yfhQ- (b), yfhR- (c), yfhs- (d) and sspE-specific (e) RNA probes. All probes were labelled with digoxigenin as described in Methods. Each lane contained $10 \mu \mathrm{g}$ total RNA from $B$. subtilis wild-type strain 168 at $t_{-2}$ (lanes 1), $t_{-1}(2), t_{0}(3), t_{1}(4), t_{2.5}(5)$, or $t_{5}$ (6). rRNA positions are indicated (23S, $2.93 \mathrm{~kb} 235$ rRNA; 165, $1.55 \mathrm{~kb} 16 \mathrm{~S}$ rRNA).

(Haldenwang, 1995) (Table 3 and Fig. 3a). Also the -35 regions of P2 and P1 do not seem to match any of the known promoter consensus sequences, but they are
$100 \%$ identical to each other. This suggests that they are recognized by the same regulatory protein or an unknown $\sigma$ factor. 


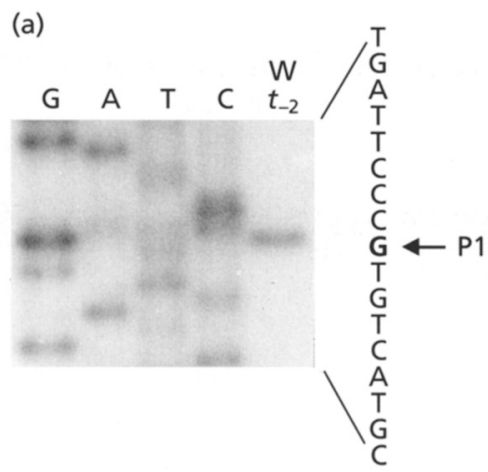

(b)

(e)
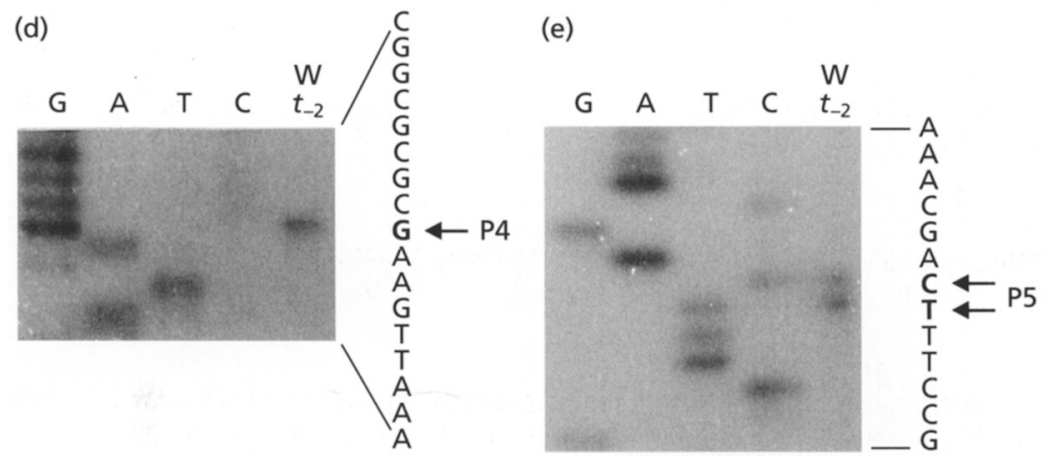
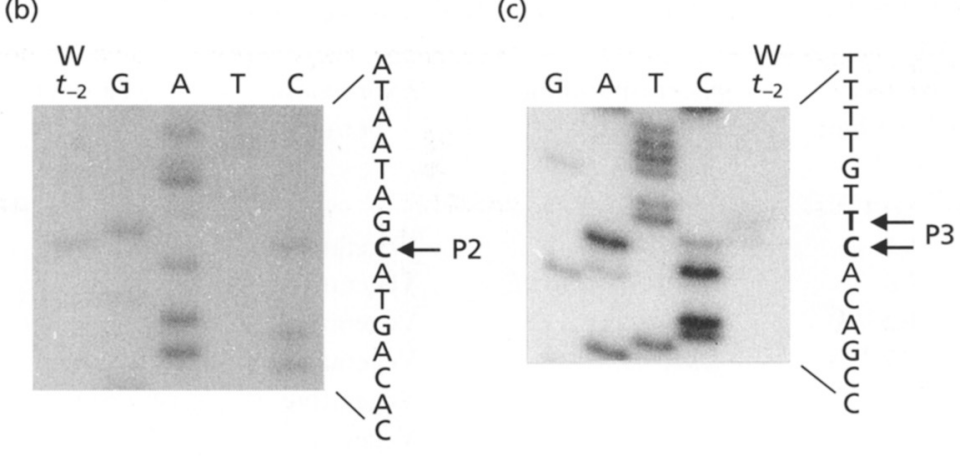

(f)

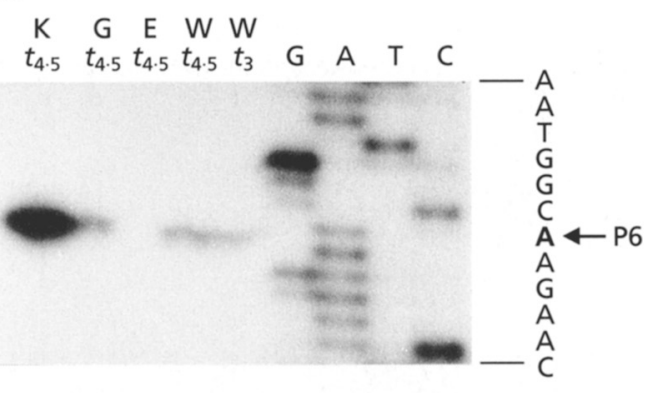

Fig. 3. Determination of transcriptional start points by primer extension analysis. RNA ( $40 \mu g$ in panels $a, b, d$ and $f$, and $20 \mu \mathrm{g}$ in panels $\mathrm{C}$ and e) from $B$. subtilis wild-type strain $168(\mathrm{~W})$ at $t_{-2}, t_{3}$ or $t_{4.5}, B$. subtilis IS60 $\left(\sigma^{\mathrm{E}} ; \mathrm{E}\right)$ at $t_{4.5}, B$. subtilis spolliG $\Delta 1\left(\sigma^{G} ; \mathrm{G}\right)$ at $t_{45}$ and $B$. subtilis IS38 $\left(\sigma^{\mathrm{K}} ; \mathrm{K}\right)$ at $t_{45}$ was hybridized with primers yfhP-ex1 (a), yfhQ-ex1 (b), yfhR-ex3 (c), yfhR-ex2 (d, e) and yfhs-ex1 (f). Sequencing reactions (GATC) were performed using the respective oligonucleotides as primers. The positions of the products are indicated by arrows to the right of the sequences.

The $5^{\prime}$ end of the $y f h S$ transcript was determined by using primer yfhS-ex1. The corresponding signal was obtained with RNA from the cells at $t_{3}$ and $t_{4 \cdot 5}$ (Fig. 3f). The signal was also obtained at $t_{45}$ with RNA from the spolIIG $\Delta 1\left(\sigma^{\mathrm{G}}\right)$ and IS38 $\left(\sigma^{\mathrm{K}}\right)$ mutants, but not from the IS60 $\left(\sigma^{\mathrm{E}}\right)$ mutant (Fig. 3f). These results show that $y f h S$ is transcribed by $\mathrm{E} \sigma^{\mathrm{E}}$. The -35 (GCGTATA) and -10 (CAAACAAT) regions spaced $15 \mathrm{bp}$ apart found upstream of P6 (Table 3 and Fig. 4b) are very similar to those of the $\sigma^{\mathrm{E}}$ consensus [ZHATAXX for the -35 region and CATACAHT for the -10 region and a spacing of $14 \mathrm{bp}(\mathrm{Z}$ is $\mathrm{T}$ or $\mathrm{G}, \mathrm{H}$ is $\mathrm{A}$ or $\mathrm{C}, \mathrm{X}$ is $\mathrm{A}$ or $\mathrm{T})$; Losick \& Stragier, 1992; Haldenwang, 1995].

\section{Insertional inactivation of $y f h P, y f h Q, y f h S, y f h R$ and sspE, and measurement of $\beta$-galactosidase activity}

Disruptants YFHPd, YFHQd, YFHSd, YFHRd and SSPEd were constructed as described in Methods. Most of the mutants did not exhibit changes in the tested phenotypes compared to the wild-type strain, the exception being the growth rate of YFHRd. In Schaeffer medium the growth rate of YFHRd was about two times lower than that of the wild-type (see Fig. 6a). Since the growth rate of YFHRd on minimal medium was, however, nearly identical to that of the wild-type strain (data not shown), the $y f h R$ gene product seems not to be essential.

An insertion of a pMUTIN1 derivative results in transcriptional fusion with lacZ. We measured the $\beta$ galactosidase activities of all mutants in Schaeffer medium. Transcription of $y f h P, y f h Q$ and $y f h R$ was observed during exponential growth (Fig. 5a, b), consistent with the results of Northern blot and primer extension analyses. The maximum activity of YFHRd was approximately 80 units $(\mathrm{mg} \text { protein })^{-1}$, whereas that of YFHQd was about sixfold lower (Fig. 5a, b). These results support the transcription of $y f h R$ from four promoters (P2, P3, P4 and P5), confirming the primer extension results (Fig. 4a, b). We also constructed transcriptional lacZ fusion strains AMP2 and AMP345 with the P2 and the P3, P4 and P5 promoters, respectively, at the $a m y E$ locus. These fusion strains expressed higher lac $Z$ activity than the control (AMLZ) (Fig. 5e), thus providing evidence of the P2-P5 promoters. Transcription of $y f h S$ was observed during sporulation (Fig. 5b), consistent with the results of Northern blot and primer extension analyses (Figs 2d and 3f). Moreover, the spoIIID mutant did not exhibit $y f h S$ expression (Fig. 5d). Since spoIllD encodes a 
(a)

cataggtgac ctcctggcag ggtgatcctg cacattcact ttgtaagaaa ttccccattt tcatatacce aattttaaa ctgattcaat cgttctcata 100

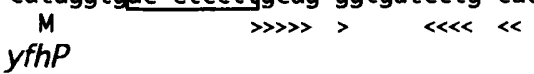

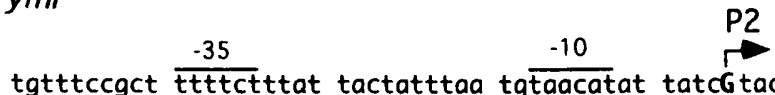

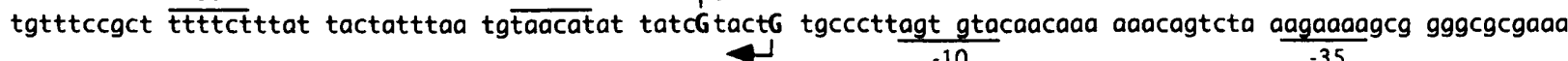
$y f h Q$
gactgdggag aacacatat $g \quad 221$
$M$

(b)

yfhQ 21

acaagctgat atcagtgatc tgcaaggtgt agtcgagcat gttttcaccc acctggtatg gaatatttca gtgtttttcg gtaaagtaaa acaAG tgtcg

T2

ccatctcgge tgctccgtaa accattctta atcgtaagag acgcgcgtgc cgtggctgta gtccgcttca ttgcgcttca ttccgccgcg cgCttcaatt

aaagaactat acgctacaag gagatggga $\underset{M}{\operatorname{yaaatg}} \quad 536$

Fig. 4. Nucleotide sequences around the putative promoter regions. Nucleotide numbers 1-221 in panel (a) and 1-536 in panel (b) correspond to regions 25015-25235 and 26123-26658, respectively, of the sequence deposited in the DDBJ database as D85082. The deduced amino acid sequence of $Y$ fhS (b), the methionine residues corresponding to the putative translational start codons of $Y f h P(a), Y f h Q(a)$ and $Y f h R(b)$, and the C-terminal region of YfhQ (b) are shown in single-letter code. Potential ribosome-binding sites are boxed and a putative T2 terminator is indicated by arrows. Transcriptional start points and directions are shown by capital letters and hooked arrows, respectively. The - 10 and -35 sequences of $\mathrm{P} 1$ and $\mathrm{P} 6$ are underlined; those of P2, P3 and P5 are overlined. The promoter sequence of P4 was not assigned. Asterisks and converging arrowheads indicate stop codons and the deduced stem-loop structure, respectively.

sporulation transcription factor that modulates the expression of both $\mathrm{E} \sigma^{\mathrm{E}}$ and $\mathrm{E} \sigma^{\mathrm{K}}$ dependence genes (Halberg \& Kroos, 1994), this result also supports the theory that $y f h S$ is transcribed by $\sigma^{\mathrm{E}}$ RNA polymerase. We examined sporulation and germination, spore heat resistance and transcription of sspE in YFHSd. No significant difference between the wild-type and $y f h S$ deficient strains was found (data not shown). Recently, it was reported that cse 60 , which encodes an acidic product comprising only 60 aa, was transcribed by $\mathrm{E} \sigma^{\mathrm{E}}$ during sporulation, but a deletion mutant of it did not show any distinctive germination rate or the coat protein profile phenotype compared with the wild-type strain (Henriques et al., 1997). YfhS is also an acidic 74 aa polypeptide and is expressed in the mother cell. There- fore, the function of the small acidic proteins during the sporulation phase remains unknown.

In the case of SSPEd, strong transcription from the $\mathrm{E} \sigma^{\mathrm{G}}$ promoter (P7) has been observed during sporulation (Hackett \& Setlow, 1987; Fajardo-Cavazos et al., 1991). Weak activity was also detected during the exponential growth phase (Fig. 5a). These results support the Northern blot analysis data (Fig. 2e). The $\beta$ galactosidase activity of SSPEd at $t_{-2}$ and $t_{-1}$ was approximately fivefold lower than that of YFHRd (Fig. $5 a$ ). We constructed $B$. subtilis SELZ, containing a $s s p E-l a c Z$ translational fusion at the $s s p E$ locus, to confirm whether $\mathrm{SspE}$ is translated during this period. $\beta$ Galactosidase activity of SELZ was not detected during 

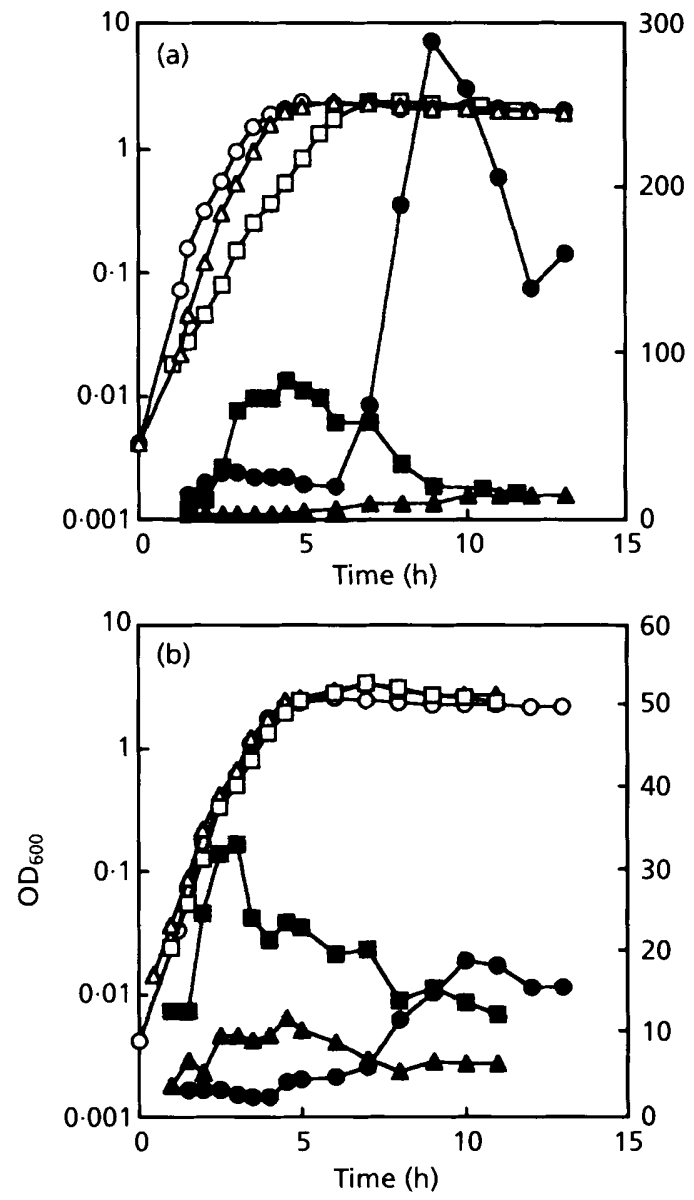

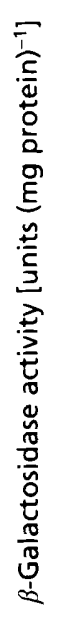

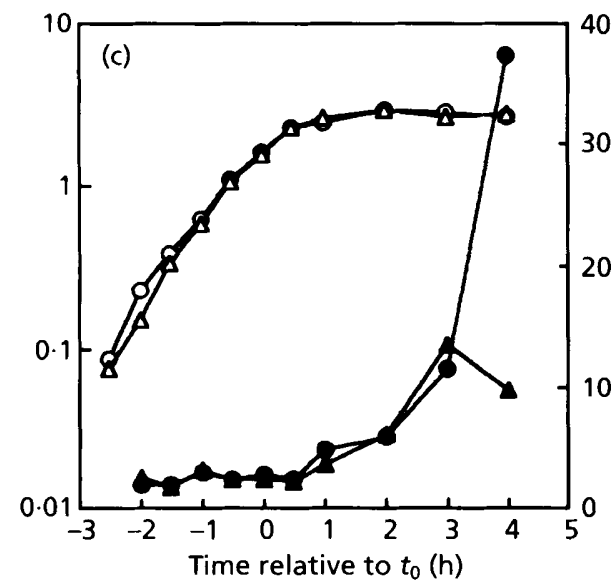

Fig. 5. Growth and $\beta$-galactosidase activity of various transcriptional fusion strains $(a, b$ and d), a sspE-lacZ translational fusion strain (c) and promoter-lac $Z$ fusion strains at the amyE locus (e). All strains were grown in Schaeffer medium at $37^{\circ} \mathrm{C}$. Open and filled symbols indicate the growth rate and $\beta$ galactosidase activity, respectively. (a) $\triangle, \boldsymbol{\Delta}$, wild-type; $\square, \boldsymbol{\square}$, YFHRd (yfhR::lacZ); $0, \mathbf{0}$ SSPEd (sspE::lacZ). (b) $\triangle, \quad \Delta$, YFHQd (yfhQ::lacZ); $\square, \mathbf{0}$, YFHPd (yfhP::lacZ); $O$, O, YFHSd (yfhs::/acZ). (c) $\triangle$, $\Delta$, wild-type; $O$, SELZ (sspE-lacZ translational fusion). (d) $\triangle$, A, HSIIID (spollID yfhS::lacZ); 0,0 , YFHSd (yfhS::lacZ). (e) A, AMLZ (control); - AMP2 (P2::lacZ); 口, AMP345 (P3-P4-P5::lacZ).

the exponential growth phase (Fig. 5c). Therefore, sspE was co-transcribed with $y f h Q$ and/or $y f h R$, but not translated.

The lack of the $y f h P$ gene product affects the transcription of both the yfhQ-yfhR-sspE and yfhP operons

Our data suggest that $y f h P, y f h Q$ and $y f h R$ are expressed during early vegetative growth. To determine whether or not the $y f h P$ gene product has some effect on the expression of $y f h Q$ and $y f h R$, we performed Northern blot analysis with RNAs derived from YFHPd. Transcripts of $2.6,1.5$ and $1.3 \mathrm{~kb}$ in YFHPd reproducibly increased compared to the wild-type strain at $t_{-2}$ and $t_{-1.5}$ (Fig. 6a). The quantities of the 1.5 and $1.3 \mathrm{~kb}$ transcripts in YFHPd at $t_{-1.5}$ were $3 \cdot 4$ - and $2 \cdot 1$-fold higher than those in the wild-type strain, respectively (Fig. 7). The relative activity of P2 in YFHPd was approximately $5 \cdot 3$-fold at $t_{-2}$ (Figs $6 \mathrm{a}$ and 7 ). These results suggest that $\mathrm{Y}$ fhP may influence the transcription of the $y f h Q-y f h R-s s p E$ operon during the exponential 


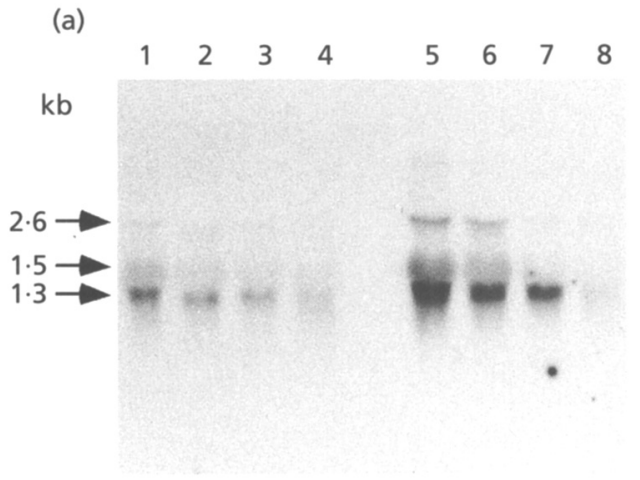

(b)

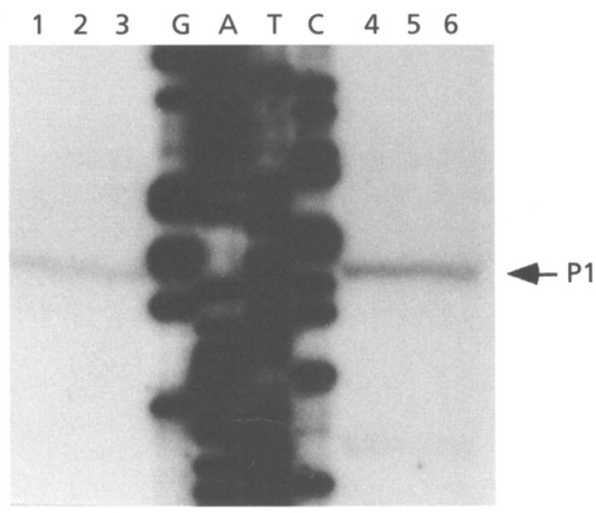

Fig. 6. Effect of the $y$ fhP mutation on the transcription of both the $y$ fhQ-yfhR-sspE and $y f h P$ operons. (a) Northern blot analysis was performed with the $y$ fhR-specific RNA probe. Each lane contained $10 \mu \mathrm{g}$ total RNA from $B$. subtilis wild-type strain 168 at $t_{-2}$ (lane 1$), t_{1.5}(2), t_{-1}$ (3) and $t_{-0.5}(4)$, or $B$. subtilis YFHPd (yfhP) at $t_{-2}$ (5), $t_{-1.5}$ (6), $t_{-1}$ (7) and $t_{-0.5}$ (8). (b) Quantitative primer extension analysis was performed with the yfhP-ex1 primer and $50 \mu \mathrm{g}$ total RNA samples from $B$. subtilis 168 (lanes $1-3$ ) and $B$. subtilis YFHPd (4-6) at $t_{-2}$ (1 and 4), $t_{-1.5}$ ( 2 and 5 ) and $t_{1}$ ( 3 and 6 ).

growth phase. As shown in Figs 6(b) and 7, the transcript initiated at P1 in YFHPd had increased approximately 2.5 -fold at $t_{-2}$ compared to the wild-type strain. These data indicate that the transcription of $y f b P$ is regulated by its own product.

We searched for recognizable sequences or structures around the promoter regions. A possible stem-loop structure $\left(\Delta G=-15 \cdot 4 \mathrm{kcal} \mathrm{mol}^{-1}\right)$, located just upstream of the putative Shine-Dalgarno sequence of $y f h P$, was found (Fig. 4). It is not still clear whether this structure is a regulatory element, such as an operator, with respect to the expression of both the $y f h Q-$ $f h R-s s p E$ and $y f h P$ operons. A similar case has been reported in the $B$. subtilis major autolysin operon which includes $c w l B(l y t C)$ encoding a $50 \mathrm{kDa} N$-acetylmuramoyl-L-alanine amidase (Kuroda \& Sekiguchi, 1991; Kuroda et al., 1992; Lazarevic et al., 1992). The product of $l y t R$, which is transcribed divergently from the $c w l B$ operon, acts as a negative regulator of the expression of both the $l p p X(l y t A)-c w b A(l y t B)-c w l B$ (lytC) and lytR operons (Lazarevic et al., 1992).

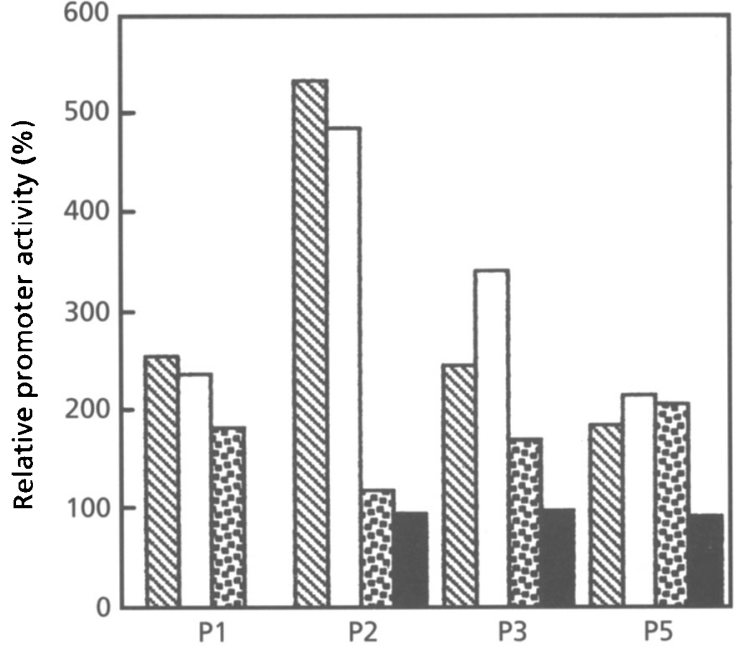

Fig. 7. Effect of the $y f h P$ mutation on the transcriptional activity of both the $y f h Q-y f h R-s s p E$ and $y f h P$ operons. Reverse transcripts or hybridization signals were quantified by Phosphorlmager or NIH Image analyses, respectively, and the relative ratio of YFHPd $(y f h P)$ to the wild-type strain for each signal was calculated. $\mathrm{P} 1$ indicates the $\mathrm{P} 1$-initiated transcript in Fig. $6(\mathrm{~b}) . P 2, P 3$ and $P 5$ indicate the mRNA species corresponding to the $2.6,1.5$ and $1.3 \mathrm{~kb}$ transcripts in Fig. 6(a), respectively. Hatched, open, dotted and filled bars indicate the relative promoter activities at $t_{2,} t_{1.5,} t_{1}$ and $t_{0.5}$, respectively.

In this study, we have shown that the $y f h Q, y f h R$ and $s s p E$ genes of $B$. subtilis form an operon for which the $y f h P$ gene product plays a regulatory role. In our future studies, we aim to determine the physiological roles of this operon.

\section{ACKNOWLEDGEMENTS}

We would like to thank Drs D. Ehrlich and D. J. Henner for providing plasmids pMUTIN1 and pDH88, respectively, and Dr P. Setlow for providing a spolllG mutant, spolliG $\Delta 1$. This research was supported by grant JSPS-RFTF96L00105 from the Japan Society for the Promotion of Science.

\section{REFERENCES}

Anagnostopoulos, C. \& Spizizen, J. (1961). Requirements for transformation in Bacillus subtilis. J Bacteriol 81, 741-746.

Fajardo-Cavazos, P., Tovar-Rojo, F. \& Setlow, P. (1991). Effect of promoter mutations and upstream deletions on the expression of genes coding for small, acid-soluble spore proteins of Bacillus subtilis. J Bacteriol 173, 2011-2016.

Hackett, R. H. \& Setlow, P. (1987). Cloning, nucleotide sequencing, and genetic mapping of the gene for small, acid-soluble spore protein gamma of Bacillus subtilis. J Bacteriol 169, 1985-1992.

Halberg, R. \& Kroos, L. (1994). Sporulation regulatory protein SpollID from Bacillus subtilis activates and represses transcription by both mother cell-specific forms of RNA polymerase. $J$ Mol Biol 243, 425-436.

Haldenwang, W. G. (1995). The sigma factors of Bacillus subtilis. Microbiol Rev 59, 1-30. 
Henner, D. (1990). Inducible expression of regulatory genes in Bacillus subtilis. Methods Enzymol 185, 223-228.

Henriques, A. O., Bryan, E. M., Beall, B. W. \& Moran, C. P., Jr (1997). cse15, cse60, and csk22 are new members of mother-cellspecific sporulation regulons in Bacillus subtilis. J Bacteriol 179, 389-398.

Kunkel, B., Sandman, K., Panzer, S., Youngman, P. \& Losick, R. (1988). The promoter for a sporulation gene in the spoIVC locus of Bacillus subtilis and its use in studies of temporal and spatial control of gene expression. J Bacteriol 170, 3513-3522.

Kunst, F., Ogasawara, N., Mozer, I. \& 148 other authors (1997). The complete genome sequence of the Gram-positive bacterium Bacillus subtilis. Nature 390, 249-256.

Kuroda, A. \& Sekiguchi, J. (1991). Molecular cloning and sequencing of a major Bacillus subtilis autolysin gene. J Bacteriol 173, 7304-7312.

Kuroda, A. \& Sekiguchi, J. (1993). High-level transcription of the major Bacillus subtilis autolysin operon depends on expression of the sigma $\mathrm{D}$ gene and is affected by a $\sin (f l a D\rangle$ mutation. I Bacteriol 175, 795-801.

Kuroda, A., Rashid, M. H. \& Sekiguchi, J. (1992). Molecular cloning and sequencing of the upstream region of the major Bacillus subtilis autolysin gene: a modifier protein exhibiting sequence homology to the major autolysin and the spoIID product. J Gen Microbiol 138, 1067-1076.

Lazarevic, V., Margot, P., Soldo, B. \& Karamata, D. (1992). Sequencing and analysis of the Bacillus subtilis lytRABC divergon: a regulatory unit encompassing the structural genes of the $\mathrm{N}$-acetylmuramoyl-L-alanine amidase and its modifier. J Gen Microbiol 138, 1949-1961.
Losick, R. \& Stragier, P. (1992). Crisscross regulation of cell-typespecific gene expression during development in B. subtilis. Nature 355, 601-604.

Michaels, M. L., Pham, L., Nghiem, Y., Cruz, C. \& Miller, J. H. (1990). MutY, an adenine glycosylase active on G-A mispairs, has homology to endonuclease III. Nucleic Acids Res 18, 3841-3845.

Sambrook, J., Fritsch, E. F. \& Maniatis, T. (1989). Molecular Cloning: a Laboratory Manual, 2nd edn. Cold Spring Harbor, NY: Cold Spring Harbor Laboratory.

Schaeffer, P., Millet, J. \& Aubert, J. P. (1965). Catabolic repression of bacterial sporulation. Proc Natl Acad Sci USA 54, 704-711.

Shimotsu, H. \& Henner, D. J. (1986). Modulation in Bacillus subtilis levansucrase gene expression by sucrose, and regulation of the steady-state mRNA level by sacU and sacQ genes. J Bacteriol 168, 380-388.

Vagner, V., Dervyn, E. \& Ehrlich, S.D. (1998). A vector for systematic gene inactivation in Bacillus subtilis. Microbiology 144, 3097-3104.

Volker, U., Engelmann, S., Maul, B., Riethdorf, S., Volker, A., Schmid, R., Mach, H. \& Hecker, M. (1994). Analysis of the induction of general stress proteins of Bacillus subtilis. Microbiology 140, 741-752.

Yamamoto, H., Uchiyama, S. \& Sekiguchi, J. (1996). Cloning and sequencing of a $27.8 \mathrm{~kb}$ nucleotide sequence of the $79^{\circ}-81^{\circ}$ region of the Bacillus subtilis genome containing the sspE locus. DNA Res 3, 257-262.

Received 13 October 1998; revised 31 March 1999; accepted 12 April 1999. 